\title{
CONGENITAL HEART DISEASE
}

\section{Quality of life in adults with congenital heart disease}

\author{
D A Lane, G Y H Lip, T A Millane
}

Heart 2002;88:71-75

See end of article for authors' affiliations

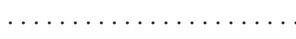

Correspondence to: Dr T Millane, Department of Cardiology, Arden House, City Hospital NHS Trust, Birmingham B18 7QH, UK; teri.millane@

cityhospbham.wmids.nhs.uk

Accepted 3 April 2002
Objective: To examine the quality of life of adults with congenital heart disease.

Design and setting: Observational, cross sectional study conducted at one general hospital in Birmingham, UK.

Patients: All 471 patients registered at the adult congenital heart disease clinic were sent the 36 item short form health survey (SF-36) to assess their quality of life. Questionnaires were completed by 276 $(58.6 \%)$ patients $(41.7 \%$ men; median (interquartile range) age $31.0(26.3-36.0)$ years, range $16-85$ years).

Results: Surprisingly, patients deemed surgically cured (for example, atrial septal defect repair) had significantly poorer quality of life in all domains (all $p<0.05$ ), except for pain, than the general population, as determined from population normative data. Patients who had received palliative treatment reported quality of life scores similar to those who had never required cardiac surgery and to the general population, although both patient groups had significantly poorer physical functioning and overall general health perception than the general population (all $p<0.01$ ). Patients with inoperable conditions had significantly poorer physical functioning (all $p<0.01$ ) and overall general health perception (all $p<0.05$ ) than all other patients, and significantly worse quality of life in all domains than the similarly aged general population. Patients with cyanotic conditions had significantly worse quality of life than age and sex matched acyanotic patients (all $p<0.01$ ).

Conclusions: Patients with inoperable or cyanotic conditions and, paradoxically, those deemed surgically cured, had the poorest quality of life among adults with congenital heart disease. However, all adults with congenital heart disease had significantly poorer levels of physical functioning and overall general health perception then similarly aged people in the general population.
C ongenital heart disease is no longer limited to paediatric clinical practice. Medical and surgical advances have resulted in most children with congenital heart disease surviving to adulthood. ${ }^{12}$ Unfortunately, for many patients with congenital heart disease further investigation and surgical intervention are necessary, and medical treatment and follow up are often life long. ${ }^{3}$ It is apparent from clinical practice that the cardiac lesion is not always the major problem for these patients, whereas issues pertaining to quality of life, such as employment, exercise participation, and pregnancy, predominate.

The World Health Organization defined health as "a state of complete physical, mental, and social wellbeing and not merely the absence of disease or infirmity". ${ }^{4}$ Thus, it is important to address not only physical health but also the emotional state and social functioning, together with occupational performance. Quality of life is a multidimensional construct that encompasses these four domains. ${ }^{5}$

Over the past 15 years interest in the quality of life among patients with congenital heart disease has increased. Despite this interest, little is known about the day to day functioning and wellbeing of adults with congenital heart disease. The majority of studies have investigated the psychosocial adjustment and development of children and adolescents with congenital heart disease ${ }^{67}$ but have not explicitly examined quality of life. To date, studies have assessed quality of life in terms of marital status, employment status, level of physical activity, educational achievement, and number of natural offspring, rather than objectively assessing quality of life by using standardised measures. ${ }^{8-11}$ Studies that have attempted to assess quality of life have usually included patients with relatively simple cardiovascular abnormalities, such as ventricular septal defect, and isolated aortic or pulmonary stenosis, ${ }^{89}$ or have examined one particular diagnostic group. ${ }^{12}$ However, these studies report that quality of life and patients' personal health assessments were comparable with those of the general population..$^{812}$

The present study aimed at evaluating quality of life in all adult patients with congenital heart disease registered at the Adult Congenital Heart Disease clinic in Birmingham, UK.

\section{METHODS}

\section{Patients}

All patients, aged 16 years or older on 1 January 2000, registered at the Adult Congenital Heart Disease clinic at City Hospital, Birmingham, were eligible for inclusion in the study. Four hundred and seventy one eligible patients were identified by our computerised database. Demographic data including age, sex, and ethnicity, as well as clinical data relating to the anatomical diagnosis, current clinical status, and present clinical management, were also established from the computerised database. Cyanosis was defined as an arterial oxygen saturation of $<90 \%$ at rest. To preserve anonymity, all patients were allocated a study number and data were collected by a non-clinical member of the team. The research protocol was approved by the ethics committee review board before the start of the study and all study participants provided informed consent.

Patients were assigned to one of five treatment categories: firstly, curative cardiac surgery ("surgically cured" group); secondly, anatomical correction with a possible requirement of a further operation ("surgically corrected" group); thirdly, palliation with or without anticipation of further surgery ("surgically palliated" group); fourthly, no clinical indication to date for cardiac surgery or intervention ("medical" group); and fifthly, conditions deemed inoperable apart from organ transplantation ("inoperable" group). Table l presents the anatomical diagnoses in each of these five treatment categories and the number of patients with each diagnosis in 
Table 1 Anatomical diagnoses in each category according to current clinical management $(n=471)$

\begin{tabular}{|c|c|c|c|c|c|c|}
\hline \multirow[b]{2}{*}{ Anatomical diagnosis } & \multicolumn{5}{|c|}{ Current clinical management } & \multirow[b]{2}{*}{ Total } \\
\hline & $\begin{array}{l}\text { Surgically } \\
\text { cured }\end{array}$ & $\begin{array}{l}\text { Surgically } \\
\text { corrected }\end{array}$ & $\begin{array}{l}\text { Surgically } \\
\text { palliated }\end{array}$ & Medical & Inoperable & \\
\hline VSD & 33 & 4 & $2 \dagger$ & 50 & $4 \dagger$ & 93 \\
\hline Pulmonary valve disease & 37 & 5 & 0 & 22 & 0 & 64 \\
\hline Coarctation of the aorta & 1 * & 61 & 0 & 1 & 0 & 63 \\
\hline Tetralogy of Fallot & 0 & 54 & $1 \neq$ & 0 & 2 & 57 \\
\hline Aortic valve disease (including subaortic stenosis) & 3 & 26 & 0 & 27 & 0 & 56 \\
\hline Secundum ASD & 22 & 0 & $2 \dagger$ & 7 & 0 & 31 \\
\hline Ostium primum septal defect & 0 & 16 & 0 & 0 & $1 \dagger$ & 17 \\
\hline D-TGA with or without VSD & 0 & 0 & 13 & 0 & 0 & 13 \\
\hline Complete AVSD & 0 & 4 & 0 & 0 & 6 & 10 \\
\hline Tricuspid atresia & 0 & 0 & 9 & 0 & 0 & 9 \\
\hline L-TGA with or without VSD & 0 & 0 & 4 & 3 & $1 \dagger$ & 8 \\
\hline VSD and ASD & 5 & 0 & $1 \dagger$ & 1 & 0 & 7 \\
\hline Pulmonary atresia/VSD & 0 & 0 & 5 & 0 & 2 & 7 \\
\hline Ebstein's anomaly & 0 & 5 & 0 & 1 & 0 & 6 \\
\hline Marfan's syndrome & 0 & 0 & 0 & 6 & 0 & 6 \\
\hline Patent ductus arteriosus & 6 & 0 & 0 & 0 & 0 & 6 \\
\hline Partial/total APVD & 4 & 0 & 0 & 0 & 0 & 4 \\
\hline Congenital conduction abnormalities & 0 & 2 & 0 & 2 & 0 & 4 \\
\hline Isolated mitral valve disease & 0 & 2 & 0 & 2 & 0 & 3 \\
\hline Atrial isomerism & 0 & 0 & 3 & 0 & 0 & 3 \\
\hline $\begin{array}{l}\text { Other (truncus arteriosus, atrioventricular tunnel defect, double inlet } \\
\text { left ventricle, dilated cardiomyopathy) }\end{array}$ & 0 & 0 & 2 & 1 & 1 & 4 \\
\hline Total & 111 & 179 & 42 & 122 & 17 & 471 \\
\hline
\end{tabular}

APVD, anomalous pulmonary venous drainage; ASD, atrial septal defect; AVSD, atrioventricular septal defect; TGA, transposition of the great arteries; VSD, ventricular septal defect.

*Thoracic vascular ring; †severe pulmonary hypertension; †other cardiac malformations.

each category. In addition, patients with cyanotic conditions were age and sex matched by a ratio of 3:1 with acyanotic patients to examine the effects of chronic hypoxia on quality of life.

All eligible patients were sent a questionnaire package in May 2000. This questionnaire permitted verification of the social and demographic data: age, sex, ethnicity, occupational status, and marital status. In addition, patients completed the standard UK version of the medical outcomes study 36 item short form health survey (SF-36). ${ }^{13}$ Patients were given six weeks to return their questionnaire.

\section{Instrument}

The SF-36 is a generic measure, which uses a multiple item scale to assess each of the following eight health concepts: physical functioning, general health, mental health, role limitations caused by physical health problems, energy/vitality, role limitations caused by emotional problems, social functioning, and bodily pain. For each of the eight health concepts, scores range from 0 to 100 , where a higher score indicates a better health state. ${ }^{14}$ The SF-36 is not designed to give an overall composite score.

The SF-36 has acceptable internal consistency and testretest reliability. An analysis of the SF-36's internal consistency found Cronbach $\alpha$ coefficients for the scales ranging from $0.73-0.96$, with a median of 0.95 in a general population study conducted in the UK. ${ }^{15}$ Studies of test-retest reliability gave Pearson product moment correlation coefficients ranging from $0.60-0.81$, with a median of $0.76 .{ }^{15}$ The lower test-retest coefficients may result from an actual change in health state, which is apt to fluctuate over time. The SF-36 is also strongly correlated with other well established measures of quality of life. ${ }^{16}$ Data were also compared with similarly aged population normative data from the UK. ${ }^{14}$

\section{Statistical methods}

Data were analysed using SPSS for Windows, version 8.0 (SPSS Inc, Chicago, Illinois, USA). All statistical tests were two tailed; $p \leqslant 0.05$ was considered significant. All categorical variables were compared using the $\chi^{2}$ statistic. Age is presented as median and interquartile range. Given the non-parametric distribution of age, a Kruskal-Wallis test was used to examine differences in age between patients in the five treatment categories. The main outcome measure was quality of life in each of the eight domains assessed by the SF-36. These data are presented as mean (SD) and compared by independent $t$ tests. Comparisons between patient data and population normative data, and comparisons between cyanotic and age and sex matched acyanotic patients were also undertaken using independent $t$ tests. Tukey post hoc tests were used to assess differences in the eight domains of quality of life between patients in each of the treatment categories.

\section{RESULTS}

\section{Baseline characteristics of the eligible patients}

Of the 471 questionnaires sent to eligible patients, 276 (58.6\%) were completed. Of those not returned, 14 (3\%) were subsequently discovered to have been sent to the wrong postal address, and 7 (1.5\%) were not completed by patients with communication difficulties (dysphasia (one), psychosis (one), profound learning difficulties (five)). A further 50 (11\%) questionnaires were not returned by 20 persistent clinic nonattenders and 30 patients previously lost to follow up for more

Table 2 Baseline characteristics of the eligible patients $(n=471)$

\begin{tabular}{|c|c|c|}
\hline Variable & $\begin{array}{l}\text { Participants } \\
(n=276)\end{array}$ & $\begin{array}{l}\text { Non-participants } \\
(n=195)\end{array}$ \\
\hline Median (IQR) age (years) & $\begin{array}{l}31.0 \\
(26.3-36.0)\end{array}$ & $\begin{array}{l}31.0 \\
(26.0-36.0)\end{array}$ \\
\hline Mens (\%) & $115(41.7)$ & $100(51.3)^{*}$ \\
\hline \multicolumn{3}{|l|}{ Study groups } \\
\hline Surgically cured (\%) & $68(24.6)$ & 43 (21.9) \\
\hline Surgically corrected (\%) & 105 (38.0) & 74 (37.9) \\
\hline Surgically palliated (\%) & $23(8.3)$ & 19 (9.7) \\
\hline Medical (\%) & $70(25.4)$ & $52(26.5)$ \\
\hline Inoperable (\%) & $10(3.6)$ & $7(3.6)$ \\
\hline
\end{tabular}


Table 3 Quality of life by treatment category based on current clinical management compared with population normative data

\begin{tabular}{|c|c|c|c|c|c|c|}
\hline & \multicolumn{5}{|c|}{ Treatment categories } & \multirow[b]{2}{*}{$\begin{array}{l}\text { Population } \\
\text { normative } \\
\text { values }\end{array}$} \\
\hline & $\begin{array}{l}\text { Surgically cured } \\
(n=68)\end{array}$ & $\begin{array}{l}\text { Surgically } \\
\text { corrected } \\
(n=105)\end{array}$ & $\begin{array}{l}\text { Surgically } \\
\text { palliated }(n=23)\end{array}$ & Medical $(n=70)$ & $\begin{array}{l}\text { Inoperable } \\
(n=10)\end{array}$ & \\
\hline $\begin{array}{l}\text { Median (IQR) age (years) } \\
\text { Quality of life category (mean (SD)) }\end{array}$ & $32.0(26.0-36.0)$ & $31.0(27.0-37.0)$ & $31.0(29.0-34.0)$ & $30.0(25.8-36.3)$ & $31.0(27.0-40.0)$ & \\
\hline Physical functioning ( $n=274)$ & $77.1(27.8)^{* * *}$ & $82.2(22.4)^{*}$ ** & $69.1(27.4)^{*} \boldsymbol{I}^{*}$ * & $85.8(21.2)^{*} \S^{* *}$ & $39.1(30.4)^{*} \dagger \ddagger \S 9$ & 92.6 (14.8) \\
\hline Role - physical $(n=267)$ & $78.1(37.1)^{*}$ & $78.0(37.5)^{*}$ & $72.7(40.8)$ & $86.2(31.1)$ & $53.6(44.3)^{*}$ & $88.5(27.9)$ \\
\hline Role - emotional $(n=267)$ & $70.7(42.4)^{*}$ & $76.3(36.5)$ & $80.3(36.6)$ & $83.6(32.7)$ & $66.7(42.2)$ & $82.8(32.7)$ \\
\hline Social functioning $(n=274)$ & $73.5(28.4) * \mathbb{\pi}$ & $82.0(24.6)^{* * *}$ & $79.3(24.0)$ & $85.9(24.3) \dagger^{* *}$ & $58.8(29.5)^{*} \neq \mathbb{\coprod}$ & $88.4(18.6)$ \\
\hline Mental health $(n=275)$ & $64.8(22.4)^{*} \neq \uparrow$ & $73.6(17.9) \dagger$ & $65.9(20.8)$ & $76.7(17.3) t^{* *}$ & 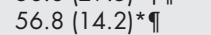 & $72.9(16.7)$ \\
\hline Energy/vitality ( $n=275$ ) & $53.2(26.1)^{*}$ & $61.5(23.5)^{* *}$ & $56.3(22.0)$ & $63.9(21.8)^{* *}$ & $35.0(22.5)^{*} \pm \mathbb{\Upsilon}$ & $60.3(19.3)$ \\
\hline Pain $(n=273)$ & $79.1(28.0)$ & $82.3(24.6)^{* *}$ & $86.0(21.8)^{* *}$ & $81.0(25.9)$ & $58.9(34.4)^{*} \ddagger \S$ & $83.8(20.3)$ \\
\hline General health perception $(n=275)$ & $58.2(27.3)^{* * *}$ & $64.7(27.0)^{* * *}$ & $57.3(26.4)^{* * *}$ & $67.4(24.3)^{* * *}$ & $26.9(20.8)^{*} \dagger \ddagger \S$ ฯ & 76.3 (18.9) \\
\hline
\end{tabular}

than 10 years. Table 2 presents the baseline demographic and clinical data for the 276 participating patients. Also presented are the analogous data for the 195 patients who did not participate. There were few significant differences between participants and non-participants, except the latter were more likely to be men $(p=0.04)$. Importantly, there were no significant differences between participants and nonparticipants in terms of their age $(p=0.64)$ or treatment category based on their current clinical management $(p=0.96)$. The participants ranged in age from 16-85 years, with a median (interquartile range) age of 31.0 (26.3-36.0) years. Women constituted $58.3 \%$ of the sample population. The majority of the participants were white $(85.6 \%)$, employed $(67.0 \%)$, and currently married or cohabiting $(53.5 \%)$.

\section{Quality of life parameters}

Table 3 presents the mean (SD) score of the eight health related concepts of quality of life by treatment category and population normative data for people aged 30-34 years*. ${ }^{11}$ The median age was similar in each of the five treatment categories $(p=0.73)$.

\section{Comparison between patient groups}

The surgically cured group had poorer mental health than the surgically corrected group $(p=0.027)$. Compared with patients in the medical study group, the surgically cured had significantly poorer social functioning $(\mathrm{p}=0.038)$ and mental health $(p=0.003)$. Surgically palliated patients did not differ from other surgical patients in any aspect of quality of life assessed but had poorer physical functioning than medical patients $(p=0.033)$. Overall, there were few differences in the eight health related concepts of quality of life between the three groups who had undergone cardiac surgery.

As expected, patients with inoperable conditions had a poorer quality of life in all areas than patients in the other four treatment categories. In particular, patients with inoperable conditions had significantly poorer physical functioning (all $\mathrm{p}<0.01$ ) and a worse general health perception (all p < 0.05) than all other patients. In addition, their scores for social functioning and energy/vitality were significantly lower than those of either the medical group $(\mathrm{p}=0.015$ and $\mathrm{p}=0.003$, respectively) or the surgically corrected group $(\mathrm{p}=0.049$ and $\mathrm{p}=0.006$, respectively) but, paradoxically, similar to those of the surgically cured group. The inoperable group also reported

*Mean, mode, and median age of the participants fell in this age range. significantly more pain than patients in the surgically palliated $(p=0.046)$ and surgically corrected groups $(\mathrm{p}=0.05)$.

\section{Comparison with population norms}

Compared with population normative data, ${ }^{11}$ the mean quality of life scores of the surgically palliated and medical groups were similar to the general population. However, the surgically cured group had significantly lower mean scores on each of the dimensions of quality of life assessed (all $p<0.05$ ), except for pain $(p>0.10)$, than the similarly aged general population. Patients in the surgically corrected group had significantly poorer quality of life in four of the eight areas assessed: physical functioning $(\mathrm{p}<0.001)$, role limitations caused by physical problems $(p<0.01)$, social functioning $(p<0.01)$, and overall general health perception $(p<0.001)$. In the inoperable group mean scores on all quality of life dimensions were significantly lower than for the general population, except for role limitations caused by emotional problems $(p>0.10)$. Physical functioning and overall general health perception was significantly lower in all congenital heart disease groups than in the similarly aged general population (all $\mathrm{p}<0.01)$.

\section{Cyanotic versus acyanotic group}

To investigate the effects of chronic hypoxia on quality of life, 19 respondents with a cyanotic condition were age and sex matched by a ratio of 3:1 with acyanotic respondents (table 4). The cyanosed group had conditions that were either surgically palliated $(n=10)$ or inoperable $(n=8)$. The cyanosed group had significantly poorer quality of life in seven of the eight health related concepts assessed by the SF-36 than age and sex matched acyanotic patients (all p $<0.01$ ). The only area of

Table 4 Quality of life in cyanotic and acyanotic patients

\begin{tabular}{lll}
\hline Quality of life category & Cyanotic $(n=18)$ & Acyanotic $(n=54)$ \\
\hline Physical functioning & $48.1(29.8)$ & $84.6(20.1)^{*}$ \\
Role - physical & $53.6(44.8)$ & $83.8(33.5)^{*}$ \\
Role - emotional & $64.1(46.1)$ & $78.8(37.9)$ \\
Social functioning & $65.3(29.6)$ & $82.8(26.6)^{*}$ \\
Mental health & $60.6(19.2)$ & $73.5(18.5)^{*}$ \\
Energy/vitality & $46.7(24.6)$ & $62.5(20.4)^{*}$ \\
Pain & $68.5(31.5)$ & $86.9(21.5)^{*}$ \\
General health perception & $39.0(29.9)$ & $66.2(25.3)^{*}$ \\
\hline \multirow{2}{*}{ Data are mean (SD). * $p \leqslant 0.05}$. & \\
\end{tabular}


quality of life in which cyanotic patients did not have poorer quality of life than acyanotic patients was role limitations caused by emotional problems $(p=0.096)$.

\section{DISCUSSION}

This is the first study to the authors' knowledge that has objectively examined quality of life among adult patients with all types of congenital heart disease using a validated measure. As expected, the present study found that patients with inoperable conditions had a trend towards a poorer quality of life in each of the eight health concepts assessed than patients with congenital heart disease in the other four treatment categories. However, a significant difference was evident only in terms of poorer physical functioning and overall general health perception. Furthermore, patients with inoperable or cyanotic conditions had a significantly worse quality of life in all areas, except for restrictions in everyday activities resulting from emotional problems, than the similarly aged general population and age and sex matched acyanotic patients, respectively.

Contrary to expectation, surgically cured patients reported significantly poorer scores in almost every aspect of quality of life assessed, except for pain, than similarly aged people in the general population. This finding is of particular importance given that many of these patients are often discharged from routine follow up at specialised congenital heart disease clinics. These patients were indistinguishable from those who had undergone either corrective or palliative cardiac surgery in terms of quality of life scores. The possible reasons for this are myriad. Firstly, the psychological scar of the thoracic incision is evident subjectively in some patients at every outpatient visit. It is possible that such childhood trauma together with the "wrapped in cotton wool" attitude prevailing 20 years ago contributes to the reduced quality of life perceived by the now adult patients. In this scenario, behavioural therapy may be beneficial. Secondly, it is possible that there are occult haemodynamic restrictions, perhaps relating to postoperative right ventricular dysfunction, limiting physical ability in adult life. This study did not examine exercise capacity directly; this is certainly an avenue for further investigation particularly with recent evidence linking exercise capacity with wellbeing. ${ }^{17}$ Thirdly, patients who have undergone curative cardiac surgery may have unrealistic expectations and therefore perceive their quality of life to be diminished. Fourthly, it is also possible that the "disease" mindset is perpetuated by following up these "cured" patients. However, follow up of such patients allows the clinician to gain experience of as yet unknown long term complications (particularly important in patients who have undergone ventriculotomy) and to act on any findings appropriately and equitably. Such follow up is quite unlike that in other fields of hospital cardiology where the emphasis is on treatment of active problems or monitoring of the inevitable.

The present finding that surgically palliated patients reported a similar quality of life to medical patients, except for poorer physical functioning among the former, was unexpected, given that many palliated patients face the prospect of further reparative surgery and are often severely physically limited. Furthermore, comparison with population normative data showed that surgically palliated patients and medical patients had similar quality of life scores to the general population. Perhaps patients who have undergone palliative surgery have adjusted to and learnt to cope with their health problems and limitations and thus do not experience a poorer quality of life. There is also the concept of not missing that which one has never had.

All patients with congenital heart disease had poorer physical functioning and overall general health perceptions than the similarly aged population. Therefore, interventions to improve physical functioning in all adult patients with congenital heart disease should be developed and implemented. The poorer physical functioning among patients with congenital heart disease may result from physical restrictions imposed by clinicians and parents during childhood and adolescence, a practice that was prevalent among such patients until quite recently. There is accumulating evidence that exercise reduces emotional distress among patients with coronary artery disease. ${ }^{17}$ Therefore, appropriate referral to cardiac rehabilitation programmes to improve physical activity in a "safe" environment, in addition to vocational and psychological counselling, where appropriate, will hopefully reduce emotional distress and worries about exercising, with subsequent improvements in other aspects of quality of life.

Protocols for identification and management of patients with remediable issues relating to poorer quality of life perception are not yet part of routine outpatient follow up. Such protocols would need to include a standard measure of quality of life (such as the SF-36) repeated at particular time intervals, preferably starting in the paediatric or adolescent service. Support from a clinical psychologist would be invaluable, as would cardiac rehabilitation as discussed above. Equity of access must be addressed for patients managed outside specialist units. Resources are limited in many health systems; adult congenital heart disease is a small field in the overall setting of heart disease but affects patients at a formative stage of social, emotional, and economic development, and may thus be judged worthy of particular attention.

\section{Limitations}

The main limitation of the present study was the cross sectional design, which depends on patients returning the questionnaires. This is a common problem, inherent in previous studies of psychosocial problems in adults with congenital heart disease. ${ }^{78}$ However, despite the modest response rate, the participants did not differ significantly from the nonparticipants in terms of age or diagnosis based on current clinical management, although responders were more likely to be women. While our service follows up all patients with operated congenital heart disease, it is inevitable that some may have been lost to follow up before referral from the paediatric service, while others, lost since then, did not return their questionnaire. Such patients presumably perceive few problems with their health and their non-inclusion in the study may have skewed the results, particularly in the surgically cured group.

Importantly, however, the present study included all adult patients with congenital heart disease rather than restricting inclusion to patients with relatively uncomplicated cardiovascular abnormalities such as ventricular septal defects, to those with pulmonary or aortic stenosis ${ }^{89}$ or to particular subgroups, ${ }^{9}{ }^{12}$ as in previous studies. As highlighted by the present study, patients with inoperable conditions or cyanotic congenital heart disease have greater impairment in many areas of quality of life; thus, it is important to assess all patients to identify the problem areas. Further, the SF-36 is a valid, reliable, and standardised measure of health related quality of life, widely used in medical research, particularly in patients with coronary artery disease and chronic medical conditions. ${ }^{1920}$

\section{Conclusions}

Medical and surgical advances have led to a dramatic decrease in mortality among patients with congenital heart disease, with the vast majority surviving to adulthood. Thus, attention should now be focused on outcomes other than death. Successful treatment depends not only on increased length of survival but also on the quality of life and need for further medical and surgical intervention. ${ }^{3}$ Interventions to increase physical functioning should be developed and implemented for all patients with congenital heart disease, with a particular 
focus on the large group of postsurgical patients who are technically cured yet report much poorer than expected quality of life in all areas except pain. The smaller group of patients with cyanotic or inoperable conditions may also benefit from directed exercise therapy. Quality of life in all patients with congenital cardiovascular abnormalities should become an important factor in the ongoing assessment of outcome of medical and surgical treatment.

\section{ACKNOWLEDGEMENTS}

Supported by a City Hospital NHS Trust Minor Research Grant.

\section{Authors' affiliations}

D A Lane, *G Y H Lip, University Department of Medicine, City Hospital, Birmingham B18 7QH, UK

T A Millane, Department of Cardiology, City Hospital

*Also the Department of Cardiology

\section{REFERENCES}

1 Cetta F, Lichtenberg RC, Clark SE. Adults with congenital heart disease. Compr Ther 1992;18:33-7.

2 Skorton DJ, Garson A. Training in the care of adult patients with congenital heart disease. Cardiol Clin 1993;11:717-20.

3 Perloff JK. Congenital heart disease in adults: a new cardiovascular subspecialty. Circulation 1991;84:1881-90.

4 World Health Organization. The constitution of the World Health Organization. WHO Chron 1947; 1:29.

5 Fallowfield $\mathbf{L}$. The quality of life: the missing measurement in health care. London: Souvenir Press, 1990.

6 Demaso DR, Beardslee WR, Silbert AR, et al. Psychological functioning in children with cyanotic heart defects. J Dev Behav Pediatr 1990;11:289-94.

7 Utens EM, Verhulst FC, Meijboom FJ, et al. Behavioural and emotional problems in children and adolescents with congenital heart disease. Psychol Med 1993;23:415-24.
8 Gersony WM, Hayes CJ, Driscoll DJ, et al. Second natural history study of congenital heart defects: quality of life of patients with aortic stenosis, pulmonary stenosis, or ventricular septal defect. Circulation 1993;87(suppl I):152-65.

9 Meijboom F, Szatmari A, Utens E, et al. Long-term follow-up after surgical closure of ventricular septal defect in infancy and childhood. $J$ Am Coll Cardiol 1994;24:1358-64.

10 Otterstad JE, Erikssen J, Froysaker T, et al. Long-term results after operative treatment of isolated ventricular septal defects in adolescents and adults. Acta Med Scand Suppl 1986;708:1-39.

11 Kopecky SL, Gersh BJ, McGoon MD, et al. Long-term outcome of patients undergoing surgical repair of isolated pulmonary valve stenosis. Circulation 1988;78:1 150-6.

12 Saliba Z, Butera G, Bonnet D, et al. Quality of life and perceived health status in surviving adults with univentricular heart. Heart 2001;86:69-73.

13 Ware JE, Sherbourne CD. The MOS 36-item short-form health survey (SF-36). I. Conceptual framework and item selection. Med Care 1992;30:473-83.

14 Jenkinson C, Layte R, Wright L, et al. The U.K. SF-36: an analysis and interpretation manual. Oxford: Health Services Research Unit, 1996.

15 Brazier JE, Harper R, Jones NMB, et al. Validating the SF-36 health survey questionnaire: new outcome measure for primary care. BM 1992;305: 160-4.

16 McHorney CA, Ware JE, Rogers W, et al The validity and relative precision of MOS short- and long-form health status measures and Dartmouth COOP charts: results from the medical outcomes study. Med Care 1992;30(suppl):MS253-65.

17 Milani RV, Lavie CJ, Cassidy MM. Effects of cardiac rehabilitation and exercise training programs on depression in patients after major coronary events. Am Heart J 1996;132:726-32.

18 Utens EM, Verhulst FC, Erdman RA, et al. Psychosocial functioning of young adults after surgical correction for congenital heart disease in childhood: a follow-up study. J Psychosom Res 1994;38:745-58.

19 Failde I, Ramos I. Validity and reliability of the SF-36 health survey questionnaire in patients with coronary heart disease. J Clin Epidemiol 2000;53:359-65.

20 Schlenk EA, Erlen JA, Dunbar-Jacob, et al. Health-related quality of life in chronic disorders: a comparison across studies using the MOS SF-36. Qual Life Res 1998;7:57-65.

\section{IMAGES IN CARDIOLOGY}

\section{Congenital bilateral coronary fistulae}

A asymptomatic 7 week old infant presented with a soft continuous murmur at the left sternal border and decreased volume femoral pulses. Both the chest radiograph and ECG were unremarkable. Echocardiography revealed an aortic coarctation and dilatation of the right aortic sinus. Colour flow mapping showed heavy flow in the right coronary artery and a fistulous communication with the left atrium. Angiography showed bilateral coronary fistulae from the right and left coronary sinuses with drainage to the left atrial appendage and coarctation (see figs: CA, coarctation of the aorta; FT, fistulous tract; LAA, left atrial appendage; LCF, left coronary fistula; RCA, right coronary artery; RCF, right coronary fistula). The right coronary artery and the ascending aorta were greatly dilated, suggesting an underlying aortopathy. An extended end-to-end repair of the coarctation via a left thoracotomy was undertaken. The smaller left coronary fistula was visualised and ligated. The patient made an uneventful recovery.

At the age of 9 months surgical exploration via a median sternotomy was undertaken to allow safe closure of the right coronary fistula. A large aneurysmal origin of the right coronary orifice was found. The fistulous tract descended posteriorly, between the aortic root and the roof of the left atrium, discharging into the base of the left atrial

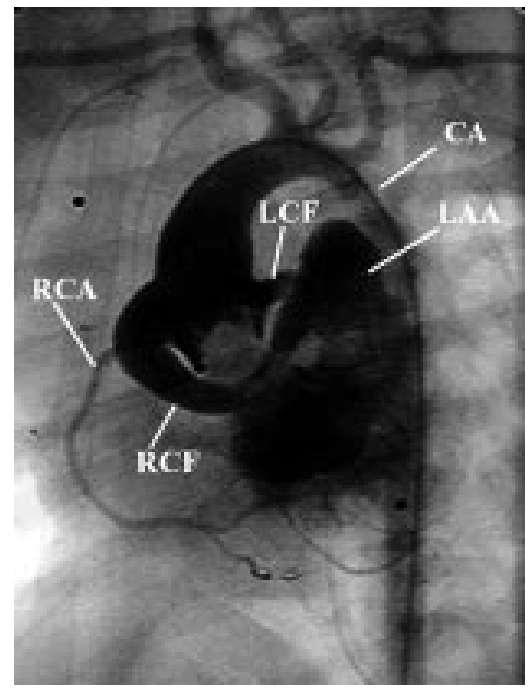

appendage. A bovine patch was sutured to the free edge of the origin of the fistulous aneurysm to protect the origin of the right coronary. The distal end of the fistulous tract was then closed with a liga clip. Recovery was uneventful and the patient remains well at 18 months follow up. The differential diagnosis of a continuous murmur includes

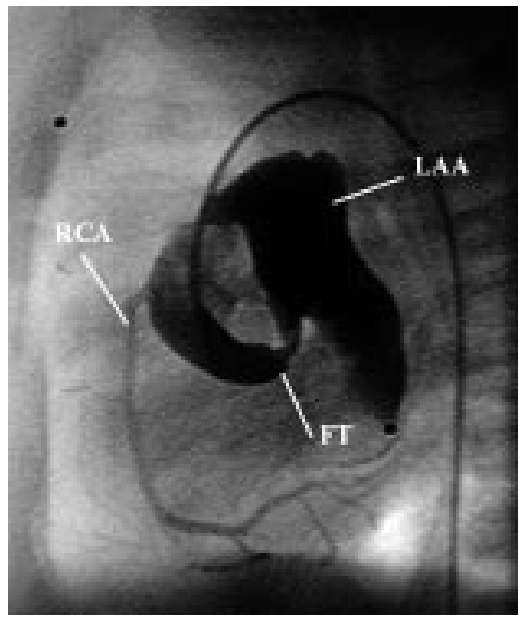

a persistent arterial duct and, more rarely, an arteriopulmonary window or an arteriovenous fistula.

K S Roman

J J Vettukattil

roman@roman99.freeserve.co.uk 